\title{
Research Paper: How to be Prepared as a Disaster Nursing: An Interview Study With Nursing Students in Indonesia
}

\author{
Felix Ljunggren $^{1}$ (D) Ingrid Lindén Moen $^{1}$ (D), Kristina Rosengren ${ }^{1,2^{*}}$ (D) \\ 1. Institute of Health and Care Science, Sahlgrenska Academy, University of Gothenburg, Gothenburg, Sweden \\ 2. Department of Internal Medicine, Sahlgrenska University Hospital, Mölndal, Sweden.
}

\begin{tabular}{l|l}
\hline $\begin{array}{l}\text { Use your device to scan } \\
\text { and read the article online }\end{array}$ \\
Students in Indonesia. Health in Emergencies and Disasters Quarterly. 2019; 5(1):53-62. http://dx.doi.org/10.32598/hdq.5.1.334.1
\end{tabular}

\section{(i) (8)}

Article info:

Received: 02 May 2019

Accepted: 25 Aug 2019

Available Online: 01 Oct 2019

\section{Keywords:}

Disaster nursing, Indonesia, Nursing students, Qualitative content analysis, Suffer

\section{A B S T RACT}

Background: Indonesia is home to approximately 400 active volcanoes located on three different tectonic plates, which put it at risk of natural disasters. Accordingly, healthcare in emergencies and disasters is of great importance in Indonesia. Therefore, this study aimed at describing nursing students' experiences of nursing education in disaster nursing in a university in Indonesia.

Materials and Methods: This qualitative content analysis with an inductive approach was conducted by semi-structured interviews with eight nursing students from a university in Indonesia.

Results: One category, namely, "Being prepared for a natural disaster", and three subcategories, namely, "Feeling prepared in nursing", "Managing limitations in nursing education" and "Managing uncertainty in nursing", were identified. Nursing students considered that theory in disaster nursing was valuable; however, they lacked reality-based education to feel be prepared to perform the required tasks as forthcoming nurses.

Conclusion: Increased and repeated practical training using case studies in nursing education is important for improving nursing students' preparedness in disaster nursing.

\section{Intoduction}

A

Powerful earthquake occurred in Asia in 2004 and caused subsequent tsunamis that struck the coast of Thailand, as well as human suffering and property damage. One survivor described said: "I didn't find my daughter until ninth months after the wave came. I was really suffering during that period of time". Relatives become patients when suffering affects several dimensions of human life, and consequently, they need support from health professionals. Therefore, nurses must be prepared to provide emergency care when a disaster occurs to ensure a high quality of healthcare for all involved (patients and relatives), which is a difficult task due to limited supplies of clean water, food, medications, dressing materials, etc. The present study aimed at improving the knowledge of disaster nursing by describing nursing students' experiences through disaster nursing.

The World Health Organization [1] defines natural disasters as earthquakes, tsunamis, volcanic eruptions, landslides and hurricanes, with long-lasting physical, biological and social impacts on individuals' health, 
well-being and survival. Every year natural disasters kill around 90000 people, and approximately 160 million people are affected worldwide. According to the Center for Research of the Epidemiology of Disasters [2], 335 disasters affected six continents of Asia (greatest number of deaths), Africa, Oceania, Europe, and North and South America (largest financial losses). Natural disasters affect society, particularly in developing countries, due to the simply constructed houses [3]. Indonesia lies in a volcanic region (400 active volcanoes) between three different tectonic plates making it vulnerable to natural disasters. In 2004, Aceh Province was hit by a strong earthquake that resulted in 170000 deaths due to a tsunami. Moreover, regular volcanic eruptions cause burns and acute respiratory infections $[1,4]$.

Nurses are a crucial part of the healthcare network as they provide health and well-being, prevent illnesses or disabilities, and alleviate the suffering caused by natural disasters, which will significantly improve the quality of healthcare. Nurses' responsibilities and professional roles [5] are as follows: person-centered care, teamwork, evidence-based care, patient safety, informatics, and quality improvement [6]. Person-centered care focuses on recognizing the patient as a partner according to preferences, values and needs in a team built on open communication and mutual respect to achieve a high quality of healthcare $[7,8]$. The interprofessional collaboration uses evidence-based knowledge, clinical experience and the patient and family preferences to facilitate a high quality of healthcare and patient safety. Teamwork grounded in evidence-based knowledge improves patient safety. Information technology is a tool to achieve a high quality of care for efficient communication that supports decision-making $[6,9]$.

Nursing competencies begin to develop during nursing education; however, research highlights variations in student learning [10]. As shown in a previous study [11], $73 \%$ of the Indonesian nursing students are prepared for natural disasters. However, increased repetitions of practice in disaster nursing guided by knowledgeable instructors is important for: 1. triaging to identify health problems, 2 . initial treatment, 3 . organizing safe transferring the patient to the nearest emergency service units, and 4. teamwork [11].

The majority of European hospitals use the Manchester Triage System (MTS) to evaluate patients' needs for emergency care [12]. However, MTS is less effective for children and the elderly. Moreover, MTS is also potentially useful during waiting times in emergency units; however, trained staff is required [13]. Organizational factors, staff's experiences, and MTS influence patients' safety; therefore, assessment tools and follow-up periods are required [14]. Triaging saves lives, but health professionals face difficulties in prioritizing patients' needs due to limited resources. High priority patients require a substantial amount of available resources leading to suffering patients with a lower priority condition [15]. Furthermore, the ABCDE method is a systematic approach to provide life-saving treatment in complex clinical situations. Each letter represents a vital function: A (airways), B (breathing), $\mathrm{C}$ (circulation), D (disability) and $\mathrm{E}$ (exposure). Beginning with A, a patient's airways are assessed and treated before the next vital function $(\mathrm{B})$ is examined [15].

Emergency care requires intraprofessional teamwork built on open communication that respects each team member's values and expertise and is visualized by common decision-making to promote the patient's best interests $[6,9,11,16,17]$.

Health and well-being are dynamically and constantly changing in daily life due to the connections between the human body, soul, and spirit. Suffering occurs in daily life, with physical, mental and social consequences. However, unnecessary suffering, such as punishment or lack of care, must be avoided [18]. Although suffering can be difficult to express because of a lack of concrete language to explain pain or anxiety, nurses must be responsive to understand patients' expressions [5]. Moreover, according to a previous study [19], nursing students who accept their own limitations can increase their understanding of suffering and how it occurs. Furthermore, survivors of the Asian earthquake in 2004, described suffering as physical and psychological symptoms due to stress prompted by the need to rebuild from nothing and dealing with anger, guilt, fear, and vulnerability. These symptoms persisted for up to one year after the disaster and were related to whether and when family members were found (alive or dead) [20].

In summary, the geographical location of Indonesia put it at risk of frequent natural disasters, therefore, increasing the knowledge regarding disaster nursing is important in reducing suffering. Based on the limited number of studies on disaster nursing, the current study aimed at providing more information regarding this issue. Therefore, the aim of the study was to describe nursing students' experiences of nursing education in disaster nursing in one of the universities in Indonesia. 


\section{Materials and Methods}

\section{Setting}

This study was conducted in a state university in Indonesia officially founded in 1949 with 18 faculties (academic and vocational education). The nursing education faculty was founded in 1998 and consists of different sixweek blocks. One of these blocks is "Disaster Nursing" and is divided into seven to nine subjects/weeks: basic concepts of disaster and health, prevention/migration, disaster preparedness, disaster response and rehabilitation/recovery, and disaster simulation. Moreover, nursing students receive a bachelor's degree after four years, and then they attend a one-year internship (hospital or clinics) to fulfill the requirements to become a registered nurse (personal communication, February 25, 2019).

\section{Design}

A qualitative manifest content analysis was performed to study the experiences from a specific phenomenon, such as nursing students' experiences of education in disaster nursing [21, 22]. Furthermore, an inductive approach was chosen to record the nursing students' experiences using semistructured interviews [23].

\section{Data collection}

Snowball sampling [23], in which informants/contact persons recommend new participants was used to select informants based on the following inclusion criteria: adult nursing students $(>18$ y) studying at the specific university with approved results (pass) from the block Disaster nursing within the last two years (2017-19) with a good command of English language. The exclusion criterion was registered nurses. Potential participants were identified aided by a contact person at the university who sent out an inquiry to nursing students who met the inclusion criteria. The data collection period was ended after including eight informants (seven women and one man aged 22-24 years). Informants received oral and written information about the study background, aims, methods, voluntary participation, and confidentiality of information, and contact information of the authors. Afterward, written consent was obtained [24].

The data were collected using semi-structured interviews asking questions in the following areas: baseline characteristics, such as age, experience in healthcare, nursing education focusing on disaster nursing, experiences in natural disasters, and reflections as a forthcoming nurse in disaster nursing. Each interview started with an open- ended question: "What are your thoughts about disaster nursing?" Appropriate follow-up questions were asked to obtain a deeper understanding of the information provided in the informant's response. Positive and negative aspects of disaster nursing were explored, and clarifications and further elaboration were recorded. The interviews $(\mathrm{n}=8)$ were conducted, recorded and then transcribed verbatim [23] in March 2019 by two authors (FL and ILM).

\section{Data analysis}

Data were analyzed using qualitative manifest content analysis with an inductive approach [21, 22]. Two authors (FL and ILM) transcribed four interviews, and thereafter all data were shared between the authors. Data were reviewed several times to provide an overview of the data. Based on the considered description of nursing students' experiences with nursing education in disaster nursing in Indonesia, meaning units were identified and condensed (Table 1).

The obtained codes were created, by which the patterns reflected in condensed units were identified. The codes were generated individually and then discussed by the authors until an agreement was reached, i.e., triangulation, to prevent possible preunderstanding. Similarities and differences in patterns were described, resulting in 68 codes forming one category, being prepared for a natural disaster, and three subcategories, feeling prepared for nursing, managing limitations in nursing education and managing uncertainty in nursing (Figure 1) [21, 22].

\section{Results}

One category, namely, "being prepared for a natural disaster", and three subcategories, namely, "feeling prepared for nursing", "managing limitations in nursing education" and "managing uncertainty in nursing" were identified. All categories were based on experiences with nursing education in natural disasters for their forthcoming roles as registered nurses.

\section{Being prepared for a natural disaster}

The category of being prepared for a natural disaster is described as the importance of developing a professional role as a forthcoming nurse. Emergency care, such as disaster nursing must be included in nursing education in Indonesia because of the high risk of natural disasters. Moreover, the structure of the block disaster nursing differs from other blocks within the nursing program in terms of practical exercises/simulations. Nursing students highlighted practice as a central and valuable as- 
Table 1. The examples of the analysis process

\begin{tabular}{cccc}
\hline Meaning Unit & Condensation & Code & Subcategories \\
\hline $\begin{array}{c}\text { They are greatly concerned about disaster } \\
\text { nursing }\end{array}$ & $\begin{array}{c}\text { Concern about disaster } \\
\text { nursing }\end{array}$ & $\begin{array}{c}\text { Concern } \\
\text { feeling prepared } \\
\text { for nursing }\end{array}$
\end{tabular}

Yes. I think in East Java it is not as good as Yogyakarta. Coordination. So maybe... um ...also the coordination between the government, educational institutions and also other entities to collaborate in simulations. Or... um... campaign for socialization about the disaster or something like that. Because I notice that social media is very high... has high..
Coordination between the government and educational institutions to collaborate with simulations socialization of a disaster

$\begin{array}{cc}\text { Coordination } & \begin{array}{c}\text { Managing limita- } \\ \text { tions in nursing }\end{array} \\ & \text { Being } \\ & \text { prepared } \\ \text { for a natural } & \text { disaster }\end{array}$

No experience with disasters, afraid or run away until the disaster is over, and then maybe come from it
Managing uncer-
Uncertainty
tainty in nursing back to help, but now I run experience at first... I'm afraid, so maybe.

I want to run away and then... and then

when the disaster... disaster is over, maybe I

can come back to help. But... if the disaster

comes here... now... I would run from it. pect of their forthcoming job as a nurse; however, they lack reality-based learning during nursing education because all their practical exercises are conducted on manikins. A focus on theoretical perspectives in nursing education creates feelings of uncertainty regarding forthcoming practical work with patients and relatives.

Nursing students described the theoretical content at a very good level (high quality) with no practical applications in nursing. In addition, the informants knew that Indonesian legislation does not allow making communication with patients until the final year of their internships. However, four years of theoretical knowledge with limited practice (manikins) was described as a major obstacle. Nursing students highlighted the importance of reality-based learning during nursing education, which needs to be improved.

As forthcoming nurses, they are aware that nursing competencies should prepare them for unforeseen events, such as natural disasters. Informants highlighted the importance of being knowledgeable as health professionals when a natural disaster occurs, although access to clean water, food, medical supplies, and other provisions might be limited. Therefore, reality-based learning was announced crucial by participants to be prepared as a forthcoming nurse and provide a high quality of care to alleviate the suffering of patients and their relatives.

\section{Feeling prepared for nursing}

The subcategory of feeling prepared for nursing was described as a motivation to learn disaster nursing, which is the knowledge achieved to work as a forthcoming nurse in a country frequently affected by natural disasters. Nursing students introduced their interests in disaster nursing to be prepared for working as a nurse in Indonesia, a country that is regularly affected by natural disasters. According to the informants, the university values the course of disaster nursing as a teaching area using committed and knowledgeable lecturers, such as the experts with experience in disaster nursing, resulting

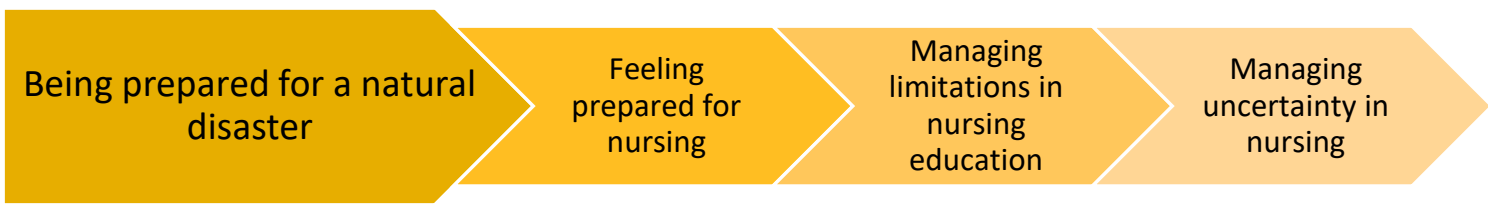

Figure 1. The category and subcategories obtained by the results 
in high-quality nursing education. Nursing students reported learning a large amount of information, which can increase their understanding of disaster nursing and is highly relevant to their upcoming professional role to alleviate suffering in the society when the infrastructure is affected by limited access to clean water, food, medical supplies, etc. Nursing students considered that knowledge in disaster nursing is valuable in daily life. They expressed feelings of hope, however a natural disaster is frightening considering their dangerous and demanding future assignments as forthcoming nurses.

I don't know... Maybe I feel like I'm happy to respond to a disaster. Because I can try to ... use all my skills to them and try to help them. Maybe I will (feel) happy, but sad at the same time. (Informant C)

Furthermore, nursing students believed that they will participate in a natural disaster through several ways during their professional careers, therefore, they were motivated to be prepared and learn the content presented in the block as much as possible. They considered the content of disaster nursing interesting, and emphasized the differences in the structure compared with other blocks. Teaching in nursing education was described mainly on theory. However, disaster nursing uses certain practical elements, such as simulations, as illustrated by the following quote:

Longer hours, longer time, more than a one-time simulation, visiting people in the red zone to know what they (know) about a disaster. About what they know when a disaster... what to do if disaster happens. (Informant B)

\section{Managing limitations in nursing education}

The subcategory of managing limitations in nursing education was described as limitations focused on the structure of nursing education. As described above, nursing students were motivated to learn disaster nursing due to regularly occurring natural disasters in the studied geographical area. However, they argued that the education structure was too general, focusing on emergency nursing instead of disaster nursing following earthquakes, eruptions, etc. Furthermore, nursing students expressed confusion about the content of the information, since the block of disaster nursing was presented before the block of emergency care, which contained similarities and differences. Therefore, they described that they were confused about the content from the blocks, which was considered as a limitation in terms of learning and developing knowledge about disaster nursing.
In addition, informants noted that morale and stress must be managed during a natural disaster, and they were concerned about experiencing fear and anxiety while managing a stressful working environment due to limited access to clean water, food, medical supplies, etc. Therefore, the informants emphasized the importance of a mixed pedagogical approach containing practical and theoretical components. For example, nursing students highlighted group work as a method for progressive learning they valued during the block. The theory of disasters provided up to date knowledge and was well communicated with satisfactory feedback from responsible lecturers. However, nursing students emphasized that a focus on general theory, for example, a definition of disasters, limited the possibility of contextualized examples of earthquakes, volcanic eruptions, floods, etc. They also described a limited period of six weeks because of the importance of the content to them and living in a country regularly affected by natural disasters.

It's not about how many skills, but how many times we can practice that skill. I think it's important. Because... we also learn many kinds of skills, but we only learn for two or three times per skill. So... after these skills are practiced... we will change to another skill and earlier skills will be kind of forgotten a little, like that. So, I the number of times we will, we can do that and also how many skills are most important... (Informant E)

The informants stated that the block's content must be developed for natural disasters focusing on practical procedures in nursing.

Furthermore, the university collaborated with other universities located in disaster-prone countries, which is associated with the high quality of knowledge in disaster nursing. However, some informants announced that studying abroad was more effective than studying in Indonesia because in other countries, theory and practice are integrated and balanced, which improves nurse's professional practice. Therefore, informants highlighted that nursing education in Indonesia should allow students to learn in real-life situations along with patients. They argued that a reliance on practical elements with manikins is not sufficient when they are preparing for emergency care and disaster nursing as follows:

When people ask "what about the disaster nursing education?" I just think about sitting in class. I think more practice is needed because if I have enough practice I can say disaster nursing is this and we use these skills. (Informant E) 
Within the block, simulations were performed to provide students an opportunity for training and measuring their knowledge about disaster nursing. Informants described this learning activity very educational but pointed out some limitations. One of the limitations was a lack of teamwork when overcoming difficulties in communicating issues within a group of members.

When I did the simulation that it was time... the situation was very chaotic. You know. Everyone wants to get help and yeah like "oh you should help me first", "No you should help me first" and yeah we have to... We should not be panic... We have to know... I have to help him or her first and then um... and then work in a team. Yeah, it's not easy. (Informant D)

Nursing student emphasized difficulties in translating theoretical knowledge into disaster nursing practice as practical exercises are not based on natural disasters. For example, simulations were described as accidents instead of natural disasters, which is the reason to emphasize the importance of specific settings, such as earthquakes, volcanic eruptions, floods, etc. by informants to increase learning in disaster nursing.

In summary, nursing students reported an imbalance between theory and practical learning, which can affect their abilities to successfully perform their forthcoming responsibilities as registered nurses in a natural disaster. Therefore, an improvement in the balance between theory and practical learning is needed.

\section{Managing uncertainty in nursing}

The subcategory of managing uncertainty in nursing was described as a lack of clinical placement of nursing students during nursing education. Nursing students experience uncertainties in performing nursing duties, particularly when unpredictable events, such as natural disasters occur. They expressed a fear of functioning as a nurse and also wishing for increased practical learning during the nursing program, i.e., applying nursing theory in nursing practice to be prepared for their future job. The informants emphasized the importance of practical exercises or internships not only using manikins during four years of education. They emphasized the importance of repeated practical elements, as they lacked the integration of theory into applied nursing.

I wish we had the emergency nursing every year, not only this last year. Because it's just before finishing and I don't feel like I'm nurse at all, because the education here, if you're a bachelor student you have no right to... practice in a hospital; so we only focus on theory and practice with fashion model. (Informant A)

Training in practical procedures on manikins at the university clinical training center was described insufficient for reality-based learning. According to nursing students, clinical practice at hospitals and clinics, where they can interact with patients can increase their abilities to manage uncertainty as forthcoming nurses, i.e., a clearer connection between theory and practice to feel secure in nursing. A lack of contact with patients during four years of nursing education leads to uncertainty in individual nursing skills. Instead, informants rely on personal life experiences of being a patient or family member, to improve their security in nursing to some extent, realizing that they have more knowledge than they previously believed.

And once I had a car accident victim who had fractures in the arms and legs, and I just immobilized them in the meantime. So that happened the fourth year after I attended the lecture and knew how to immobilize the patient with fractures. I feel really good... (Informant A)

Some informants had personal experiences with natural disasters. This reality-based learning was described crucial to alleviate uncertainty as a forthcoming nurse.

Actually, there is a good thing to learn about disasters because you know our...our country is really ... to disasters and so many disasters happen here. So, I think at least about... after I got the... I got through this block I can tell my family or friends that "I know about this and you should... maybe we can do this to prevent" maybe. (Informant D)

They use their knowledge (personal and educated) developed about disaster nursing to make friends and families aware regarding preventive measures in natural disasters, such as preparing a "disaster kit" at home that contains the necessary equipment and supplies to use in a natural disaster. This experience achieved by improved knowledge about the measures before disasters can facilitate the readiness for their forthcoming role as a nurse.

\section{Discussion}

The study aimed at describing nursing students' experiences with nursing education in disaster nursing in one of the universities in Indonesia. The results highlighted the importance of being prepared for the forthcoming job as a registered nurse in natural disasters in Indonesia. A lack of balance between theory and practice in nursing 
education influences nursing students' learning and uncertainty regarding their professional role. Moreover, informants were informed that Indonesia frequently experiences natural disasters and highlighted the importance of being prepared in hospitals and/or health centers/ clinics [25]. Nilsson et al. [26] described this preparation as a difference in competence between experienced nurses and nursing students. Manikin training alone is not sufficient to adequately prepare nursing students for clinical settings, although nursing students need conceptual training to be as realistic as possible. Therefore, case studies with former patients and/or relatives who have experienced natural disasters can be implemented in nursing education to describe their experiences, however, clinical placements are not available or allowed due to educational rules and regulations in Indonesia.

Forthcoming nurses in Indonesia are most likely to work in threatening and/or dangerous environments due to regular natural disasters; consequently, nursing students must be prepared to handle extreme working environments. Therefore, experienced nurses skilled in disaster nursing are valuable to increase the level of reality-based learning. Moreover, nursing education also must improve teamwork and loop communication [27], and also clinical placements should be considered to prepare forthcoming nurses for nursing practice. This knowledge can be used to educate patient by encouraging self-care in society [28], where resources are limited following a natural disaster in a developing country, such as Indonesia.

As mentioned above, suffering is not exclusively related to bodily pain; however, it often is spiritual/emotional suffering [18]. For example, in a previous study [20], relatives' suffering decreased after supports provided by nurses. Suffering is associated with several aspects of human life; therefore, an awareness of how suffering is expressed is an important task in nursing $[18,19]$. Nursing students with personal experiences (their own or related to a family member) with suffering, these narratives can be used as alternative learning methods/case studies along with manikins in the clinical training centers of the universities. One method is to apply drama as a forum theatre $[29,30]$ built on the pedagogy of the oppressed, related to the real-life situations of the natural disasters drawn from experiences of former patients/relatives that facilitate reality-based knowledge [20].

This method is consistent with the study by Braband et al. [31], who announced that students learn to identify and respond to suffering with no patient contact using other types of reality-based learning. Therefore, nursing students could broaden their knowledge in disaster nursing by interviewing families and friends who have experienced in disaster nursing, i.e., meeting suffered people is a prerequisite in understanding the goals and practice of nursing [19]. In Indonesia, family and society are highly valued and characterized by a willingness to help and respect each other.

Moreover, survivors experience suffering for long a period [20]. Therefore, nursing students could use narratives in nursing education to learn nursing. This finding is supported by Eriksson [18], who reported that people become suffering patients when several dimensions of human life are affected. Nursing students assume that they will face suffering caused by a natural disaster in some aspects and highlighted the importance of being prepared to promote health and well-being as needed. Interest in nursing and personal experiences can strengthen students' confidence and abilities to deliver a high quality of care in natural disasters [26].

According to our results, a limitation of theory-oriented nursing education within a short-time frame (six weeks) was highlighted, i.e., an imbalance between theory and practice. Nursing students emphasized that general knowledge does not adequately prepare them for working as a forthcoming nurse during natural disasters. A clear connection has shown between repeated simulations and improved teamwork, including closed-loop communication based on $\mathrm{ABCDE}[27,16]$ to prioritize treatments and optimize drug management. Repeated simulations integrate theoretical knowledge into practice, resulting in a deeper understanding when skills are practiced $[3,11$, $27,28]$. Adequate preparation as a forthcoming nurse is important to provide a high quality of care [26].

However, a lack of contact with patients (only manikins) causes uncertainty as a forthcoming nurse. This lack of practical skills within real-life situations occurs due to Indonesian law that does not allow students to practice on real patients before obtaining a bachelor's degree [25]. Therefore, repeated simulations and applied drama $[29,30]$ in the clinical training centers are effective to reduce uncertainty along with practical feedback from skilled lecturers who facilitated an introduction to nursing profession [17]. Teaching methods, such as narratives by experienced nursing students [31] and interviewing relatives about natural disasters can improve students' understanding of suffering in disaster nursing without violating the laws regarding patient contact during nursing education. 


\section{Limitations}

The current study intended to contribute deeper insights into the context of disaster nursing in nursing education. One limitation was that the data were only collected from one university in Indonesia. More interviews conducted in different universities might broaden the collected data by incorporating various experiences. However, a convenient small sample was related to the qualitative methods [23]. The sample was heterogeneous, although the participants were interested in and motivated to learn disaster nursing and willing to participate and share their experiences as forthcoming nurses working in a country that regularly experiences natural disasters.

Another limitation was that all interviews were performed in English, which is not the native language of either the researchers or participants and the language barriers potentially existed. However, the same openended question was used and appropriate follow-up questions were asked to obtain an understanding of the informants' responses regarding disaster nursing and clarifications and further elaborations were recorded. Moreover, the relationship between the authors and participants showed no interdependence, the settings, materials, and methods were sufficiently described, and the data were analyzed using a well-known scientific method, qualitative content analysis [21, 22].

Therefore, the methods are described as systematic qualitative research that relies on trustworthiness, transparency, verification, and reflexivity, which is helpful to develop insightful and artful interpretations within managing preparedness in nursing [23]. However, the limited number of studies on disaster nursing indicates the importance of further investigations on learning methods to improve nursing education focusing on preparedness to manage uncertainty in nursing.

\section{Conclusions}

According to the limited number of studies on nursing students' experiences of education in disaster nursing, this study broadens the knowledge regarding using reality-based topics to include theory into nursing practice. According to the content of nursing education, repetitive simulations along with case studies based on storytelling from experienced nursing students and relatives, as well as scientific articles on disaster nursing, support the learning of forthcoming nurses. Preparedness as newly educated nurses facilitates a high quality of nursing, such as providing preventative health care and promoting well-being by manage suffering.
The use of storytelling (relatives and students) about experienced natural disasters increases forthcoming nurses' awareness of disaster nursing. In addition, teamwork on mutual goals supported by knowledgeable staff members in nursing and medicine is a tool to manage a difficult working environment due to damaged infrastructure. Disaster nursing is a necessary part of Indonesian nursing students' education to prevent and alleviate suffering in unforeseen events, such as natural disasters. Because Indonesian rules and regulations forbid patient contact during nursing education, other resources are highlighted. A mix of pedagogical approaches (theory and practice) built on experienced life situations in disaster nursing and reality-based learning should be combined with repeated simulations performed in teams.

\section{Ethical Considerations}

\section{Compliance with ethical guidelines}

Ethical approval (KE/FK/0472/EC/2019) and the necessary permissions were obtained from the studied university. Ethical considerations, such as voluntary participation, informed consent, the confidentiality of the information, and no harm were considered. Written and oral information about the background, aim and methodology of the study was provided. Respect for participants was main concern regarding the right to withdraw, the confidentiality of personal data, and the reporting fruitful results for the good of society/health care. Requirements regarding ethical considerations are described in a previous study [24].

\section{Funding}

The authors received no financial support for the research, authorship, and/or publication of this article.

\section{Authors' contributions}

All authors contributed to the design, interpreted the data, and critically drafted and revised the article for important intellectual content. All the authors read and agreed to the final version of the article.

\section{Conflict of interest}

The authors declared no conflict of interest.

\section{Acknowledgments}

We thank the teachers and managers who organized the data collection, as well as nursing students who participated in the study. We also thank the LinnaeusPalme Partnership, Higher Education Council, funded 
by the Swedish International Development Cooperation Agency, Sida.

\section{References}

[1] World Health Organisation. Natural events [Internet]. 2018 [Updated 2018 December 16]. Available from: https://www.who. int/environmental_health_emergencies/natural_events/en/

[2] Centre for Research on the Epidemiology of Disasters. Annual disaster statistical review 2017 [Internet]. 2018 [Updated 2019 March 12]. Available from: https://www.cred.be/annual-disaster-statistical-review-2017

[3] Veenema TG. Managing emergencies outside of the hospital: Special events, mass gatherings, and mass causality incidents. In: Veenema TG, editor. Disaster Nursing and Emergency Preparedness for Chemical, Biological, and Radiological Terrorism and other Hazards. $2^{\text {nd }}$ ed. New York: Springer Publishing Company; 2007

[4] World Health Organisation, WHO - Regional office for SouthEast Asia. Mount Merapi Eruption - November 2010 - Indonesia. (n.d.). http://www.searo.who.int/entity/searhef/mountmerapieruption/en/ (accessed 31 March 2019)

[5] International Council of Nurses. The ICN code of ethics for nurses [Internet]. 2012 [Updated 2019 March 12]. Available from: https://www.icn.ch/sites/default/files/inlinefiles/2012_ICN_Codeofethicsfornurses_\%20eng.pdf

[6] Quality and Safety Education for Nurses. QSEN competencies [Internet]. 2019 [Updated 2019 January 19]. Available from: http:/ / qsen.org/competencies/pre-licensure-ksas/

[7] Ekman I, Swedberg K, Taft C, Lindseth A, Norberg A, Brink E, et al. Person-centered care - ready for prime time. European Journal of Cardiovascular Nursing. 2011; 10(4):248-51. [DOI:10.1016/j.ejcnurse.2011.06.008] [PMID]

[8] McCormack B, McCance TV. Development of a framwork for person-centred nursing. Journal of Advanced Nursing. 2006; 56(5):472-9. [DOI:10.1111/j.1365-2648.2006.04042.x] [PMID]

[9] Barnsteiner J, Disch J, Johnson J, McGuinn K, Chappell K, Swartwout E. Diffusing QSEN competencies across schools of nursing: The AACN/RWJF faculty development institutes. Journal of Professional Nursing. 2013; 29(2):68-74 [DOI:10.1016/j.profnurs.2012.12.003] [PMID]

[10] Jennings-Sanders A, Frisch N, Wing S. Nursing students' perceptions about disaster nursing. Disaster Management \& Response. 2005; 3(3):80-5. [DOI:10.1016/j.dmr.2005.04.001] [PMID]

[11] Alim S, Kawabata M, Nakazawa M. Evaluation of disaster preparedness training and disaster drill for nursing students. Nurse Education Today. 2015; 35(1):25-31. [DOI:10.1016/j. nedt.2014.04.016] [PMID]

[12] Zachariasse JM, Seiger N, Rood PPM, Alves CF, Freitas $\mathrm{P}$, Smit FJ, et al. Validity of the manchester triage system in emergency care: A prospective observational study. PLOS One. 2017; 12(2):e0170811. [DOI:10.1371/journal. pone.0170811] [PMID] [PMCID]
[13] Cooke M, Jinks S. Does the Manchester triage system detect the critically ill? Journal of Accident \& Emergency Medicine. 1999; 16(3):179-81. [DOI:10.1136/emj.16.3.179] [PMID] [PMCID]

[14] Forsman B, Forsgren S, Carlström C. Nurses working with Manchester triage - the impact of experience on patient security. Australasian Emergency Nursing Journal. 2012; 15(2):100-7. [DOI:10.1016/j.aenj.2012.02.001]

[15] Smith RM, Dyer GSM, Antonangeli K, Arredondo N, Bedlion $\mathrm{H}$, Dalal A, et al. Disaster triage after the Haitian earthquake. Injury. 2012; 43(11):1811-5. [DOI:10.1016/j.inn jury.2011.07.015] [PMID]

[16] Thim T, Vinther Krarup NH, Lerkevang Grove E, Rohde $\mathrm{CV}$, Løfgren B. Initial assessment and treatment with the Airway, Breathing, Circulation, Disability, Exposure (ABCDE) approach. International Journal of General Medicine. 2012; 5:117-21. [DOI:10.2147/IJGM.S28478] [PMID] [PMCID]

[17] Ingvarsson E, Verho J, Rosengren K. Managing uncertainty in nursing - newly graduated nurses' experiences of introduction to nursing profession. International Archives of Nursing and Health Care. 2019; 5(1):119. [DOI:10.23937/2469-5823/1510119]

[18] Eriksson K. [The suffering human (Den lidande människan) (Swedish)]. 2n ed. Stockholm: Liber; 2015.

[19] Eifried Sh. Bearing witness to suffering: The lived experience of nursing students. Journal of Nursing Education. 2003; 42(2):59-67.

[20] Hatthakit U. The suffering experiences of Buddhist tsunami survivors. International Journal of Human Caring. 2007; 11(2):59-66. [DOI:10.20467/1091-5710.11.2.59]

[21] Graneheim UH, Lundman B. Qualitative content analysis in nursing research: Concepts, procedures and measures to achieve trustworthiness. Nurse Education Today. 2004; 24(2):105-12. [DOI:10.1016/j.nedt.2003.10.001] [PMID]

[22] Graneheim UH, Lindgren BM, Lundman B. Methodological challenges in qualitative content analysis: A discussion paper. Nurse Education Today. 2017; 56:29-34. [DOI:10.1016/j.nedt.2017.06.002] [PMID]

[23] Polit DF, Beck CT. Nursing research: Generating and assessing evidence for nursing practice. Philadelphia: Wolters Kluwer Health; 2017.

[24] Rules \& Guidelines for Research. The humanities and social sciences [Internet]. 2019 [Updated 2020 January 30]. Available from: http://www.codex.vr.se/en/forskninghumsam.shtml

[25] Suryanto V, Plummer M, Boyle M. Healthcare System in Indonesia. Hospital Topics. 2017; 95(4): 82-89. [DOI:10.1080/ 00185868.2017.1333806] [PMID]

[26] Nilsson J, Johansson E, Carlsson M, Florin J, Leksell J, Lepp M, et al. Disaster nursing: Self-reported competence of nursing students and registered nurses, with focus on their readiness to manage violence, serious events and disasters. Nurse Education in Practice. 2016; 17:102-8. [DOI:10.1016/j. nepr.2015.09.012] [PMID]

[27] Reime M, Johnsgaard T, Kvam FI, Aarflot M, Engeberg $\mathrm{JM}$, Breivik $\mathrm{M}$, et al. Learning by viewing versus learning by doing: A comparative study of observer and participant experiences during an interprofessional simulation training. 
Journal of Interprofessional Care. 2017; 31(1):51-8. [DOI:10.1 080/13561820.2016.1233390] [PMID]

[28] Orem DE, Taylor SG. Reflections on nursing practice science: The nature, the structure, and the foundation of nursing science. Nursing Science Quarterly. 2011; 24(1):35-41. [DOI:10.1177/0894318410389061] [PMID]

[29] Morrison M, Nilsson E, Lepp M. Bringing the personal to the professional: Pre-service teaching students explore conflict through an applied drama approach. Applied Theatre Research. 2013; 1(1):63-76. [DOI:10.1386/atr.1.1.63_1]

[30] O'Toole J, Bagshaw D, Burton B, Grünbaum A, Lepp M, Morrison $\mathrm{M}$, et al. Researching conflict, drama and learning - the international DRACON project. Singapore: Springer; 2019. [DOI:10.1007/978-981-13-5916-3]

[31] Braband BJ, Gaudino R, Rogers A. Exploring students' perceptions and understanding of life-altering suffering: An interview project. International Journal of Human Caring. 2015; 19(1):49-56. [DOI:10.20467/1091-5710.19.1.49] 